\section{Diameter growth prediction for individual Pinus occidentalis Sw. trees}

\author{
Santiago Bueno-López ${ }^{(1)}$, Eddie Bevilacqua ${ }^{(2)}$
}

Predictive equations calibrated with remeasurement data from 25 permanent plots having individually identified trees were used to project stem diameter of Pinus occidentalis Sw. in Dominican Republic. The general form of the models used to fit the growth and yield functions included fixed effect covariates related to three subsets of explanatory variables: initial tree size, stand attributes, and competition indexes. The subsets were incrementally added in a stepwise fashion for each of the three response variables and the intercept of the model was allowed to vary randomly between plots. The models evaluated included a yield function that predicted future diameter at year $t\left(d_{t}\right)$, a periodic annual increment model using five-year diameter increment (id $\left.{ }_{5}\right)$ and its natural $\log$ transformation $\left[\ln \left(i d_{5}+0.01\right)\right]$. For trees that were not remeasured exactly 5 years after the first measurement, $i d_{5}$ was computed by averaging the mean annual increment nearest the 5 year point and multiplying by five. Each approach was evaluated using an independent validation data set based on seven goodness-of-fit statistics, graphical display of residuals and the variance components of each model combination. LMM, including fixed and random parameters, provided a better fit among the models tested. For estimating future diameter, accuracy of predictions is within one centimeter for a five-year projection interval, and bias is negligible. All the models had moderately improved fit statistics when random effects were included in the evaluation. The degree of improvement behaved in a similar manner for most fit statistics, with differences in the range of values for MSE, RMSE and RMSE\% of $0.53,0.23$ and 1.05 , respectively. The absolute difference between the extreme values for Bias and relative Bias (\%) in all the models was 0.20 and 0.92 . The differences in values for MAD were only 0.15 and $R^{2}$ values were practically equivalent.

Keywords: Repeated Measurements, Mixed Models, Stepwise Regression, Site Quality, Individual Tree Competition Indexes

\section{Introduction}

The development of forest growth models can help to predict yields needed to maintain harvest levels within the sustainable capacity of the forest, by providing quantitative data which will be made available to forest managers and land use planners. Informed decisions can then be made in regards to silvicultural alternatives. Access to better quantitative information through growth models will lead to increased levels of sustainable timber management.

One of the most common and important tree characteristics used in forest management decision-making is tree diameter-atbreast height (dbh). This variable has numerous beneficial attributes. It is easy to measure (Zhang et al. 2004) and have strong correlations with other tree characteristics. The distribution of trees by dbh class allows foresters and ecologists to understand stand structure, stand dynamics, and future forest yield. Individual-tree diameter growth models are among the most basic and essential components of forest growth models (San-
chez-Gonzalez et al. 2006). They allow one to project and describe the state of a tree at some future time. They also allow estimation of the growth of an average tree of a given size growing within a specified stocking level and site productivity.

In addition to its current size, a tree's competitive position will influence its growth. Most competition indexes assume that the level of competitive stress around a tree can be quantified by taking account of the number of competitors and their size within a defined neighborhood (Kiernan et al. 2008). Competition indexes may be expressed in absolute or relative terms. They can also be spatially related or not. Distance-independent models take advantage of the competitive position of a tree by comparing the relative size and condition of a subject tree to various stand characteristics, such as basal area and/or average diameter. Distance-independent growth models assume that, spatially, all sizes are uniformly distributed throughout the stand (Davis \& Johnson 1987).
(1) Vicerrectoria de Investigaciones e Innovación, Pontificia Universidad Catolica Madre y Maestra, Santiago de los Caballeros (Dominican Republic); (2) College of Environmental Science and Forestry, State University of New York, 1 Forestry Drive, 13210 Syracuse, NY (USA)

(a) Santiago Bueno-López (swbueno@gmail.com)

Received: Oct 26, 2012 - Accepted: Mar 06, 2013

Citation: Bueno-López S, Bevilacqua E, 2013. Diameter growth prediction for individual Pinus occidentalis Sw. trees. iForest 6: 209-216 [online 2013-05-27] URL: http://www.sisef.it/iforest/contents/? id=ifor0843-006

Communicated by: Marco Borghetti

Two common competition indexes based on relative stem size include: (1) the ratio of subject tree size to average tree size; and (2) the cumulative basal area of trees larger than the subject tree (BAL - Zhao et al. 2004). As the ratio of the subject tree basal area to the average tree basal area increases, the vigor of the tree is assumed to be greater and the grow rate approaches the genetic potential. BAL has been useful in predicting diameter increment (Wycoff 1990) and should be considered complementary to stand basal area. As BAL decreases, the predicted increment increases.

Predictive equations are often calibrated with remeasurement data from permanent plots having individually identified trees. The nature of repeated measures experiments is often ignored and independence between observations is assumed (Uzoh \& Oliver 2008). However, two measurements taken at adjacent units of time and/or space are more highly correlated than two measurements taken several time points or space apart. High autocorrelations can make two mutually exclusive variables appear to be related. While ignoring the least-squares regression assumptions of independence still results in unbiased estimates of the model parameters, estimates of model errors are biased (Uzoh \& Oliver 2008), bringing into question inferences of model coefficients. The argument among growth and yield researchers - i.e., that the ordinary least squares (OLS) estimates are unbiased and that more reasonable variance structure may not be necessary, since users are mainly interested in prediction - is not supported by the statistical model used because it violates the first fundamental assumption needed to apply the OLS method; it violates the assumption of independence of observations.

Previous studies showed improvements on 
model-fitting and parameter standard errors using global accuracy assessments based only on fixed effects (Zhao et al. 2004, Garrett et al. 2004, Monleon 2004). Mixed models, however, perform better if the random factors (i.e., plot or tree) are used in the prediction. Prediction of the random components using best linear unbiased predictors (BLUP) can be carried out by either using a sample of complementary observations of the dependent variable if available (Calama $\&$ Montero 2005) or by duplicating the trees in the sample and setting the second half of the data with missing values of the response variable (Zhang \& Gove 2005).

Predictor variables at the tree and stand level, such as dbh, stand density, site index and competition indexes, are included in the model as fixed effects. Under such circumstances, the appeal of using mixed models is to obtain improved estimates of model variance when observations are correlated. To account for an appropriate error term, methods based on mixed models with special parametric structures on the covariance matrices are applied. The specification of covariance structures addresses the bias in the standard error of parameter estimates (Zhang $\&$ Gove 2005). The most commonly used covariance structures for modeling repeated measurements data are compound symmetric, first-order autoregressive and unstructured (Littell et al. 1996). The most appropriate goodness-of-fit statistic used to evaluate and compare models includes Akaike's and Bayesian information criteria (Zhang et al. 2004).

Pinus occidentalis is an endemic pine species of Hispaniola that can be found growing in pure and mixed populations with broadleaf trees below 2100 meters, or in pure stands above this elevation (Farjon et al 1997). In 1995, forests of $P$. occidentalis Sw. covered an area of approximately 302500 hectares in the Dominican Republic (Dobler et al. 1995). In this country, it represents more than the $95 \%$ of the species' world-wide distribution (Bueno-López \& Bevilacqua 2012). Within the study area (La Sierra), the species covers approximately 34937 hectares, occupying $10 \%$ of this area in pure stands (Swedforest Consulting 1992). The terrain here is more than $90 \%$ mountainous with slopes often above $25 \%$ and very fragile soils, requiring the presence of forest cover to maintain soil stability.

In both Dominican Republic and Haiti, the pine forests found growing on higher elevation slopes are associated with shallow soils. Pinus occidentalis is the only commercial species having the ability to grow on these shallow, acidic, infertile soils due to their capability to establish ectomycorrhizal symbioses with various types of fungi. Other small patches can be found in Sierra de Bahoruco and towards the south in both countries.

The objectives of this paper were to: (1) determine whether OLS or linear mixed models is the best statistical technique to fit linear regression model for predicting dbh over time in $P$. occidentalis trees using tree size, elapsed time, stand attributes and competitive indexes as predictor variables; (2) determine whether future diameter or fiveyear diameter increment is the more appropriate response variable to model when predicting future $\mathrm{dbh}$; and (3) in the case of linear mixed models, determine the effectiveness of including only fixed $v s$. fixed plus random effects in the predictions of future dbh.

\section{Materials and methods}

The study area is a region of approximately $1800 \mathrm{~km}^{2}$ in the north central portion of Cordillera Central, Dominican Republic (Bueno-López \& Bevilacqua 2011). The data available for model development were from 25 natural, even-aged stands of Pinus occidentalis in three different life zones in La Sierra region. Nine stands are in the humid zone, 6 in the intermediate zone, and 10 stands in the dry region. The humid-life zone is denominated formally as "Subtropical Very Humid Forest"; the intermediate zone located between the two previously mentioned zones, is called "Subtropical Humid Forest"; the dry life zone corresponds to the formal denomination "Subtropical Dry Forest" (Holdridge 1987).

In each stand one permanent rectangular plot was located. Permanent plot data were used because they provide a direct measure of individual tree dbh growth over time and are considered the best kind of dbh growth data. Every effort was made to cover a wide range of stand conditions. Plots selected for sampling were unburned and appear free of damages from insects and or fungi. The plots were established at random from 1984 through 1991 (Tab. 1) The youngest stand measured was 21 years in its first measurement year (1988), and the oldest stand was 46 years, also in its first measurement year.

Individual trees in each plot were marked for identification. The diameter at breast height $(\mathrm{dbh}, \mathrm{cm})$ outside bark was measured to the nearest $0.1 \mathrm{~cm}$ for all trees larger than $5 \mathrm{~cm}$. The individual tree diameters were measured with a diameter tape every measurement year. Since there is not a definite growing season in the tropics, measurements were taken at approximately the same time of the year (from May, which is the end of the main raining season, to August). Total tree height $(\mathrm{m})$ was measured with a hypsometer on each tree each year.

The initial age of the trees at the first measurement spanned a range of 25 years, from 21 to 46 years. Site index ( 40 year index age) was estimated using equations de- veloped by Bueno-López (2009) and ranged from $13 \mathrm{~m}$ to $30 \mathrm{~m}$. The stands ranged in density from 192 to 950 stems ha ${ }^{-1}$ and from 9.3 to $33.4 \mathrm{~m}^{2} \mathrm{ha}^{-1}$ in basal area. Stand density index $(S D I)$ values were developed by Bueno-López (2009) following the procedure proposed by Reineke (1933). SDI was computed by the following formula (eqn. 1):

$$
S D I=N\left(\frac{25}{\bar{D}_{q}}\right)^{-1.8326}
$$

where $S D I$ is the stand density index, $N$ is the number of trees per hectare and $\bar{D}_{\mathrm{q}}$ is the quadratic mean diameter. Values ranged from 17.0 to 48.6 .

To fit and evaluate the models, the data was randomly partitioned into a model estimation and validation component (80:20 split). The estimation data set had a total of 830 trees and the validation data set 200 trees. Comparisons between the observed and predicted $\mathrm{dbh}$ at last measurement were made, as well as the periodic annual diameter growth over the total measurement period, using the best equations from the resulting models.

\section{General form of the regression models}

The general form of the models used to fit the growth and yield functions included fixed effect covariates related to three subsets of explanatory variables: initial tree size, stand attributes, and competition indexes. The subsets were incrementally added in a stepwise fashion for each of the three response variables. In addition, the intercept of the model was allowed to vary randomly between plots. Three models were evaluated in their ability to predict diameter five years after the first measurement; a yield function that predicted future diameter at year $t\left(d_{\mathrm{t}}\right)$, a periodic annual increment model using fiveyear diameter increment $\left(i d_{5}\right)$ and its natural $\log$ transformation $\left[\ln \left(i d_{5}+0.01\right)\right]$; as for the latter parameter, the constant 0.01 was added in order to compute the logarithm for those trees that had no diameter increment. For trees that were not remeasured exactly 5 years after the first measurement, $i d_{5}$ was computed by averaging the mean annual increment nearest the 5 year point and multiplying by five.

The general approach for model development included the following forms (eqn. 2, eqn. 3 , eqn. 4 ):

$$
\begin{aligned}
& Y=f(\text { tree size })+e_{j}+e_{i j} \\
& Y=f(\text { tree size, stand })+e_{j}+e_{i j} \\
& Y=f(\text { tree size, stand, competition })+e_{j}+e_{i j}
\end{aligned}
$$

where $Y$ is the future diameter at year $t\left(d_{\mathrm{t}}\right)$; five-year diameter increment $\left(i d_{5}\right)$; or natural logarithm of five-year diameter increment $\left[\ln \left(i d_{5}+0.01\right)\right]$. Tree size is the initial diameter $\left(d_{0}\right)$ and/or initial basal area $\left(B A_{0}\right)$. Stand 
Tab. 1 - Summary statistics on sample plots used for growth measurements. $(*)$ : Square meters per hectare $\left(\mathrm{m}^{2} \mathrm{ha}^{-1}\right)$.

\begin{tabular}{|c|c|c|c|c|c|c|c|c|c|c|}
\hline \multirow{2}{*}{ Zone } & \multirow{2}{*}{$\begin{array}{c}\text { Plot } \\
\text { ID }\end{array}$} & \multirow{2}{*}{$\begin{array}{l}\text { Size } \\
\text { (ha) }\end{array}$} & \multirow{2}{*}{$S D I$} & \multirow{2}{*}{$T P H$} & \multirow{2}{*}{$S I$} & \multirow{2}{*}{$B A^{*}$} & \multicolumn{2}{|c|}{ Measurement year } & \multirow{2}{*}{$\begin{array}{c}\text { Interval } \\
\text { (years) }\end{array}$} & \multirow{2}{*}{$\begin{array}{c}\text { Number of } \\
\text { measurements }\end{array}$} \\
\hline & & & & & & & Initial & Final & & \\
\hline \multirow[t]{10}{*}{ Dry } & 101 & 0.1000 & 29.12 & 250 & 22 & 14.5 & 1984 & 1989 & 5 & 6 \\
\hline & 102 & 0.1000 & 24.99 & 240 & 13 & 12.3 & 1984 & 1991 & 7 & 8 \\
\hline & 103 & 0.1000 & 29.8 & 440 & 20 & 13.8 & 1987 & 1990 & 3 & 4 \\
\hline & 108 & 0.1000 & 34.91 & 660 & 21 & 16.2 & 1989 & 1994 & 5 & 4 \\
\hline & 109 & 0.1000 & 29.6 & 580 & 18 & 13.7 & 1989 & 1994 & 5 & 4 \\
\hline & 110 & 0.1000 & 48.59 & 950 & 23 & 22.4 & 1989 & 1994 & 5 & 4 \\
\hline & 111 & 0.1000 & 20.7 & 580 & 15 & 9.3 & 1989 & 1994 & 5 & 4 \\
\hline & 112 & 0.1000 & 28.63 & 740 & 15 & 12.9 & 1989 & 1994 & 5 & 4 \\
\hline & 115 & 0.1000 & 32.45 & 350 & 21 & 15.8 & 1991 & 1995 & 4 & 2 \\
\hline & 116 & 0.1000 & 37.12 & 420 & 25 & 18 & 1991 & 1995 & 4 & 2 \\
\hline \multirow[t]{6}{*}{ Intermediate } & 1 & 0.1000 & 42.13 & 470 & 29 & 20.5 & 1988 & 1994 & 6 & 5 \\
\hline & 3 & 0.1250 & 40.14 & 336 & 28 & 15.7 & 1988 & 1994 & 6 & 5 \\
\hline & 5 & 0.1250 & 43.39 & 352 & 22 & 17 & 1988 & 1994 & 6 & 5 \\
\hline & 6 & 0.0625 & 17.01 & 192 & 23 & 13.8 & 1988 & 1991 & 3 & 4 \\
\hline & 11 & 0.0625 & 23.4 & 656 & 20 & 17.5 & 1988 & 1990 & 2 & 3 \\
\hline & 12 & 0.0625 & 25.06 & 672 & 20 & 18.7 & 1988 & 1990 & 2 & 3 \\
\hline \multirow[t]{9}{*}{ Humid } & 8 & 0.0625 & 39.48 & 832 & 27 & 30.2 & 1988 & 1994 & 6 & 5 \\
\hline & 9 & 0.0625 & 30.31 & 720 & 25 & 22.9 & 1988 & 1994 & 6 & 5 \\
\hline & 10 & 0.0625 & 31.73 & 528 & 30 & 31.3 & 1988 & 1991 & 3 & 4 \\
\hline & 13 & 0.0625 & 27.14 & 576 & 24 & 20.8 & 1988 & 1994 & 6 & 5 \\
\hline & 14 & 0.0625 & 30.07 & 656 & 23 & 22.9 & 1988 & 1994 & 6 & 5 \\
\hline & 15 & 0.0625 & 24.64 & 304 & 28 & 19.8 & 1988 & 1994 & 6 & 5 \\
\hline & 16 & 0.0625 & 35.56 & 400 & 31 & 28.8 & 1988 & 1994 & 6 & 5 \\
\hline & 17 & 0.0625 & 24.83 & 544 & 27 & 18.9 & 1988 & 1993 & 5 & 3 \\
\hline & 18 & 0.0625 & 30.3 & 592 & 25 & 23.8 & 1988 & 1991 & 3 & 4 \\
\hline
\end{tabular}

is the trees per hectare $(T P H)$, basal area $(B A)$, stand density index $(S D I)$, and Site in$\operatorname{dex}(S I)$. Competition is the initial diameterquadratic diameter ratio $\left(d_{0} / d_{\mathrm{q}}\right)$ and/or cumulative basal area of the trees larger than subject tree $\left(B A L_{0}\right) ; e_{\mathrm{j}}$ is the random error for plot $j, e_{\mathrm{ij}}$ is the random error for tree $i$ within plot $j$.

To fit the yield function - future diameter at time $t\left(d_{\mathrm{t}}\right)-$, initial tree size variables employed were diameter-at-breast height at first measurement $\left(d_{0}\right)$ and its transformations, $d_{0}^{2}$ and $\ln \left(d_{0}\right)$. Stand attributes considered included trees per hectare at first measurement $\left(T P H_{0}\right)$, basal area per hectare at first measurement $\left(B A_{0}\right)$, site index base age $40(S I)$, and stand density index at first measurement $\left(S D I_{0}\right)$. Distance independent competition indexes used were ratio of subject tree diameter to mean squared diameter $\left(C I_{0}\right)$ and cumulative basal area of the trees larger than subject tree $\left(B A L_{0}\right)$. We also incorporated elapsed time since first measurement ( $t$, years) and $t^{2}$ as fixed factors for this particular yield function. Since many of the sites are relatively poor with the trees showing moderate deceleration in growth, the inclusion of the quadratic time term allowed us to capture this reduced growth rate, even for the short time period represented by the data.

To fit a model to diameter increment $\left(i d_{5}\right)$ and its $\log$ transformation $\left[\ln \left(i d_{5}\right)\right]$, all the predictor variables described above, except time, were employed. When retransforming the variables back from natural log scale, the logarithmic bias correction factor suggested by Baskerville (1972) was used.

\section{Modeling methods}

Available data were based on a sample of repeated growth measurements taken from trees located in different plots. Plots were installed and re-measured in different years (Tab. 1), leading to the potential that observations on the same plot are likely correlated. In order to address this, a multi-level linear mixed model (LMM), including both fixed and random plot components, was tested and compared with ordinary least square (OLS) models in their capability to precisely estimate future diameter (yield function) at the end of a five year period.

To determine which LMM model was most appropriate in minimizing the mean squared error of predictions, we carried out the selection taking into consideration candidate covariance structures; fitting different models by means of restricted maximum likelihood, and using the smallest Akaike's Information Criterion to choose the most appropriate from the following candidate covariance structures (Gutzwiller \& Riffell 2007): firstorder autoregressive [AR(1)], compound symmetric (CS) and unstructured (UN).

The linear mixed model (LMM) is a special case of generalized linear models, and can be expressed as $Y=X \beta+Z \gamma+\varepsilon$ where $Y, X$ and $\beta$ are as defined in the OLS equation, $Z$ is a known design matrix, $\gamma$ is a vector of unknown random effects parameters, and $\varepsilon$ is a vector of unobserved random errors. It is assumed: (1) $\mathrm{E}(\gamma)=0$ and $\operatorname{var}(\gamma)=G$; (2) $\mathrm{E}(\varepsilon)$ $=0$ and $\operatorname{var}(\varepsilon)=R ;(3) \operatorname{cov}(\gamma, \varepsilon)=0$; and (4) both $y$ and $\varepsilon$ are normally distributed. The variance of $Y$ is $V=Z G Z^{\mathrm{T}}+R$, and can be estimated by setting up the random-effects design matrix $Z$ and by specifying covariance structures for $G$ and $R$ (Littell et al. 1996). LMM can be used to: (1) characterize or model the spatial covariance structure in the data; and (2) remove the effects of spatial autocorrelation to obtain more accurate estimates for the response variable or treatment means. In our case, the residual variation was divided into between-plot and betweentree components for the LMM evaluated.

\section{Models selection and evaluation}

Three growth and yield response variables were each fitted by OLS (stepwise selection) and LMM using PROC REG (SAS Institute Inc. 1996) and PROC MIXED (Littell et al. 1996), respectively. Predictor variables in the final OLS models were chosen based on their biological foundation and the level of significance for the parameters. In the case of the LMM, besides their biological rationale and level of significance, explanatory variables were also considered based on the estimates of the parameters in $G$ and $R$ matrices. The covariance structure was selected among three candidates: autoregressive, compound symmetry and unstructured to estimate the fixed and random effects and selecting the structure with the smallest 
Akaike's Information Criterion (AIC) and Bayesian's Information Criterion (BIC Gregoire \& Schabenberger 1995). LMM models were fitted and compared using restricted maximum likelihood methods.

The variance component for trees within plots along with the correlation between successive measurements on individual $P$. occidentalis trees endowed the best relationship for five-year diameter increment and explanatory variables which included initial diameter $\left(d_{0}\right)$ and/or initial basal area $\left(B A_{0}\right)$; trees per hectare $(T P H)$, basal area $(B A)$, stand density index $(S D I)$, and site index $(S I)$, initial diameter-quadratic diameter ratio $\left(d_{0} / d_{\mathrm{q}}\right)$ and/or cumulative basal area of the trees larger than subject tree $\left(B A L_{0}\right)$.

According to Popper (1963), the validation of a model is not intended to prove that the model is correct, but to show that model predictions are close enough to independent data (Uzoh \& Oliver 2008). Models for each dependent variable were quantitatively evaluated using an independent verification data by examining the distribution, bias and precision of residuals to determine the accuracy of model estimations (Vanclay 1994). The residuals were computed by subtracting the predicted from the observed future 5-year diameter values. Mean square error (MSE), root mean square error (RMSE), root mean square error as percentage of average observed values on the response $(R M S E \%)$, pseudo coefficient of determination $\left(R^{2}\right)$, absolute and relative bias $(B, B \%)$, and mean absolute deviation $(M A D)$ were calculated as follows (eqns. 5 - 11):

$$
\begin{aligned}
& M S E=\frac{\sum\left(d_{5 \mathrm{i}}-\hat{d}_{5 \mathrm{i}}\right)^{2}}{n-m} \\
& R M S E=\sqrt{\sum \frac{\left(d_{5 \mathrm{i}}-\hat{d}_{5 \mathrm{i}}\right)^{2}}{n}} \\
& R M S E \%=\frac{\sqrt{\frac{\left(d_{5 \mathrm{i}}-\hat{d}_{5 \mathrm{i}}\right)^{2}}{n}}}{\bar{d}_{5}} \cdot 100 \\
& R=1-\frac{\sum\left(d_{5 \mathrm{i}}-\hat{d}_{5 \mathrm{i}}\right)^{2}}{\sum\left(d_{5 \mathrm{i}}-\bar{d}_{5 \mathrm{i}}\right)^{2}} \\
& B=\sum \frac{\left(d_{5 \mathrm{i}}-\hat{d}_{5 \mathrm{i}}\right)}{n} \\
& B \%=\frac{100 \cdot\left|\sum \frac{\left(d_{5 \mathrm{i}}-\hat{d}_{5 \mathrm{i}}\right)}{n}\right|}{\bar{d}_{5}} \\
& M A D=\sum \frac{\left|d_{5 \mathrm{i}}-\hat{d}_{5 \mathrm{i}}\right|}{n}
\end{aligned}
$$

where $n$ is the number of observations in the

\begin{tabular}{|c|c|c|c|c|c|c|c|c|}
\hline \multirow{2}{*}{$\begin{array}{c}\text { Response } \\
\text { variable }\end{array}$} & \multirow{2}{*}{ Effect } & \multirow{2}{*}{ Estimate } & \multirow{2}{*}{ SD } & \multirow{2}{*}{$\begin{array}{l}\operatorname{Pr}>t \\
\text { or } Z\end{array}$} & \multirow{2}{*}{ AIC } & \multirow{2}{*}{ BIC } & \multicolumn{2}{|c|}{$\begin{array}{c}\text { Covariance Parameter } \\
\text { Estimates }\end{array}$} \\
\hline & & & & & & & $\begin{array}{l}G \text { Matrix } \\
\text { (p-value) }\end{array}$ & $\begin{array}{l}R \text { Matrix } \\
\text { (p-value) }\end{array}$ \\
\hline \multirow[t]{4}{*}{$d_{\mathrm{t}}$} & Intercept & 0.7027 & 0.1406 & $<0.0001$ & 4909.4 & 4911.8 & \multirow{4}{*}{$\begin{array}{c}0.049 \\
(0.0008)\end{array}$} & \multirow{4}{*}{$\begin{array}{c}0.3551 \\
(<.0001)\end{array}$} \\
\hline & $t$ & 0.2942 & 0.0069 & $<0.0001$ & & & & \\
\hline & $d_{0}$ & 0.9903 & 0.0042 & $<0.0001$ & & & & \\
\hline & $B A L_{0}$ & -0.0428 & 0.0040 & $<0.0001$ & & & & \\
\hline
\end{tabular}
validation dataset; $m$ is the number of $\beta_{\mathrm{i}}$ parameters, excluding $\beta_{0} ; d_{5 \mathrm{i}}$ is the observed dbh five years hence for tree $i$; $\hat{d}_{5 \mathrm{i}}$ is the predicted dbh five years hence for tree $i$; $\bar{d}_{5}$ is
Tab. 2 - Parameter estimates and fit statistic of the best model (LMM, random plus fixed effects) to estimate future diameter at breast height (dbh). (SD): Standard deviation. the mean dbh five years after initial measurement.

\section{Predictions using the LMM}

The fixed effects portion of a mixed model can be used to predict the value for the response variable if all covariates required are measured or estimated (Calama \& Montero 2005). To obtain individual predictions of the best linear unbiased predictors (BLUP's) of the random parameters for each plot, we followed the procedures outlined by Zhang \& Gove (2005). Mixed models allow predicting the value for the random parameters specific to a given plot. The coefficients vary from tree to tree, providing a model suitable to each tree in the sample (Westfall 2006) and increasing the accuracy of predictions of $d_{\mathrm{t}}$ and $i d_{5}$ based on current stand conditions.
Random components obtained in this way can be used to calibrate the diameter increment and diameter yield models.

\section{Results}

The resulting $d_{\mathrm{t}}$ equation, modeling the response variable future diameter at breast height and fitted using LMM, provided the best fit (eqn. 12):

$$
\begin{aligned}
d_{t} & =0.7027+0.2942 \cdot t+0.0903 \cdot D_{0} \\
& -0.0428 \cdot B A L_{0}+e_{j}+e_{i j}
\end{aligned}
$$

All parameters remaining in model from eqn. 12 are biologically logical and significant at $\alpha=0.001$ level (Tab. 2). The resul-

\begin{tabular}{|c|c|c|c|c|c|c|c|}
\hline \multirow{3}{*}{$\begin{array}{l}\text { Response } \\
\text { variable } \\
d_{\mathrm{t}}\end{array}$} & \multirow{3}{*}{$\begin{array}{l}\begin{array}{l}\text { Explanatory } \\
\text { variable subset }\end{array} \\
\text { Intercept }\end{array}$} & \multicolumn{6}{|c|}{ Parameter estimation and inference method } \\
\hline & & \multicolumn{3}{|c|}{ OLS } & \multicolumn{3}{|c|}{ LMM } \\
\hline & & $\mu$ & $\mu$ & $\mu$ & $\mu$ & $\mu$ & $\mu$ \\
\hline & Time & $t$ & $t$ & $t$ & $t$ & $t$ & $t$ \\
\hline & Initial tree size & $d_{0}$ & $d_{0}$ & $d_{0}$ & $d_{0}$ & $d_{0}$ & $d_{0}$ \\
\hline & Stand & - & $\mathrm{TPH}_{0}$ & $\mathrm{TPH}_{0}$ & - & ns & ns \\
\hline & Competition & - & - & $B A L_{0}$ & - & - & $B A L_{0}$ \\
\hline & $G$-matrix & - & - & - & 0.094 & 0.094 & 0.049 \\
\hline & $R$-matrix & 0.456 & 0.439 & 0.389 & 0.368 & 0.368 & 0.355 \\
\hline & AIC & 5503 & 5425 & 5106 & 5006 & 5006 & 4909 \\
\hline \multirow[t]{7}{*}{$i d_{5}$} & Intercept & $\mu$ & $\mu$ & $\mu$ & $\mu$ & $\mu$ & $\mu$ \\
\hline & Initial tree size & ns & ns & ns & $d_{0}$ & $d_{0}$ & $d_{0}$ \\
\hline & Stand & - & $\begin{array}{c}T P H_{0} \\
S D I_{0}\end{array}$ & $\begin{array}{c}T P H_{0} \\
S D I_{0}\end{array}$ & - & ns & ns \\
\hline & Competition & - & - & $B A L_{0}$ & - & - & $B A L_{0}$ \\
\hline & $G$-matrix & - & - & - & 0.188 & 0.188 & 0.123 \\
\hline & $R$-matrix & - & 0.888 & 0.745 & 0.716 & 0.716 & 0.665 \\
\hline & AIC & - & 2267 & 2131 & 2130 & 2130 & 2068 \\
\hline \multirow{7}{*}{$\ln \left(i d_{5}+0.01\right)$} & Intercept & $\mu$ & $\mu$ & $\mu$ & $\mu$ & $\mu$ & $\mu$ \\
\hline & Initial tree size & $B A_{0}$ & $B A_{0}$ & $B A_{0}$ & $B A_{0}$ & $B A_{0}$ & $B A_{0}$ \\
\hline & Stand & - & $\begin{array}{c}T P H_{0}, \\
S I_{0}, S D I_{0}\end{array}$ & $\begin{array}{l}T P H_{0}, \\
S I_{0}, S D I_{0}\end{array}$ & - & $\mathrm{TPH}_{0}$ & $\mathrm{TPH}_{0}$ \\
\hline & Competition & - & - & $B A L_{0}$ & - & - & $B A L_{0}$ \\
\hline & $G$-matrix & - & - & - & 0.155 & 0.153 & 0.070 \\
\hline & $R$-matrix & 0.697 & 0.593 & 0.510 & 0.516 & 0.516 & 0.464 \\
\hline & AIC & 1948 & 1851 & 1740 & 1768 & 1781 & 1692 \\
\hline
\end{tabular}
ting model predicts a linear trend in dbh through time, with higher rates of growth in larger trees and lower rates of growth for
Tab. 3 - Comparison of predictor variables, estimated variance components and fit statistics of individual tree growth and yield response variables for different subsets of explanatory variables and method of parameter estimation. $\left(d_{\mathrm{t}}\right)$ : future dbh at time $t ;\left(i d_{5}\right)$ : 5-year diameter increment; $\left[\ln \left(i d_{5}+0.01\right)\right]$ : natural logarithm of 5-year diameter increment; (ns): non significant. 
Fig. 1 - Comparison of observed $v s$. predicted five-year future diameter for 9 different dbh growth models. The first row were models using future $\mathrm{dbh}\left(d_{\mathrm{t}}\right)$ as the dependent variable, second row using 5-year diameter increment $\left(i d_{5}\right)$ as the dependent variable, and bottom row using natural logarithm of 5-year diameter increment $\left[\ln \left(i d_{5}\right)\right]$ as the dependent variable. Model parameter estimates of predictor variables for each dependent variable were fitted using ordinary least squares (OLS column

1), linear mixed models including only the fixed effects (LMM column 2) and linear mixed models including both fixed and random effects (LMM column 3).

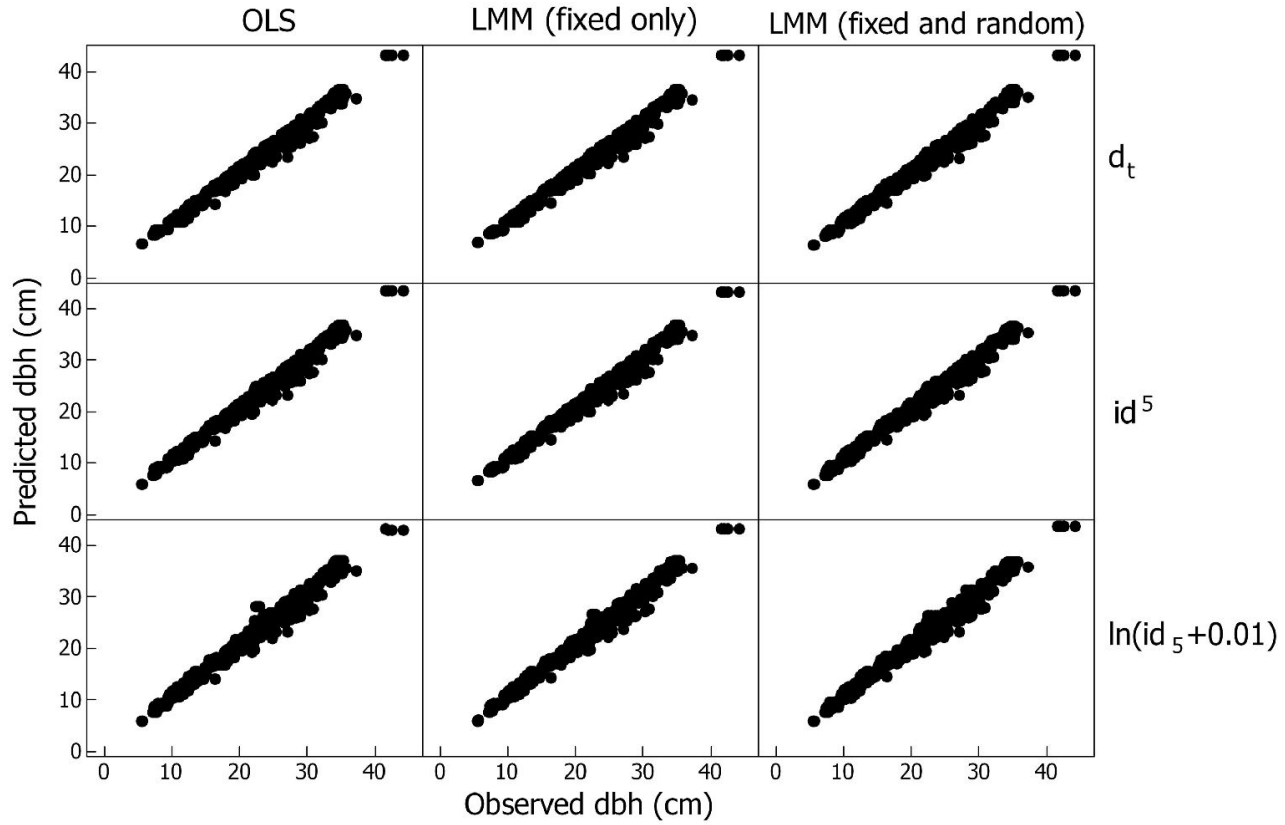

trees when the cumulative $B A$ of larger trees increases.

The random effects represented trees and plots. Future diameter at breast height in time $t\left(d_{\mathrm{t}}\right)$ is explained by elapsed time since first measurement ( $t$, years); diameter-atbreast height at first measurement $\left(d_{0}\right)$; and cumulative basal area of the trees larger than subject tree $\left(B A L_{0}\right)$.

Tab. 3 shows summary fit statistics for the best performing subsets of explanatory variables when added incrementally in a stepwise fashion for each response variable. For each response variable, $d_{\mathrm{t}}, i d_{5}$ and $\ln \left(i d_{5}+0.01\right)$, we can clearly see the progressive improvement in Akaike's Information Criterion, when stand and competition variables were added as predictor variables. We also noticed that between tree variance ( $R$-matrix) diminished as a result of adding these variables. Parameters were retained in a model if estimates made logical biological sense and were significant at $\alpha=0.05$ level.

For OLS models, stand and competition variables were statistically significant in predicting all response variables. Models that included only initial tree size as a predictor resulted non-significant for the response $i d_{5}$. $B A L_{0}$ was the only individual-tree competition variable to significantly contribute to models $d_{\mathrm{t}}$ and $i d_{5}$ (Tab. 3). For the LMM formulation, none of the stand variables were significant to the response variable $d_{\mathrm{t}}$. Between-plot random effects as indicated by the $G$-matrix, were statistically significant, indicating that the variation in individual tree growth which could be explained by stand variables was instead captured by the random plot term.

Overall, the LMM models had lower AIC and smaller between-tree variance than the models fitted by OLS. The $d_{\mathrm{t}}$ model, using the unstructured (UN) covariance structure and considering plots as random effects, pro- duced better fit statistics as compared to using $\mathrm{CS}$ and $\mathrm{AR}(1)$ variance-covariance matrices. In addition, the null model likelihood ratio test was statistically significant $(\mathrm{p}<0.0001)$, indicating that the unstructured covariance structure was adequate.

Additionally, the best OLS and LMM models for each response variable, based on AIC, were also evaluated in their capability to predict dbh of $P$. occidentalis five years after initial measurement using the independent validation data set. To accomplish this evaluation we first examined the correspondence expected between observed and predicted future diameter on the 9 different dbh growth models tested (Fig. 1). The rows on the chart depict three models for each of the response variables (the future diameter $d_{\mathrm{t}}$, diameter increment $i d_{5}$ and natural $\log$ of diameter increment $\ln \left(i d_{5}\right)$, respectively). The columns correspond to the three statistical techniques explored (ordinary least

Tab. 4 - Goodness-of-fit statistics for best six models predicting diameter at breast height (dbh) five years after initial measurement using an independent validation data set of 200 trees. Models had different response variables and parameter estimation techniques (OLS and LMM, described in text). $\left(d_{t}\right)$ : future dbh at time $t ;\left(i d_{5}\right)$ : 5-year diameter increment; $\ln \left(i d_{5}+0.01\right)$ : natural logarithm of 5-year diameter increment. $(*)$ : see text for descriptions.

\begin{tabular}{|c|c|c|c|c|c|c|c|c|c|}
\hline \multirow{4}{*}{$\begin{array}{c}\text { Goodness- } \\
\text { of-fit } \\
\text { statistics* }\end{array}$} & \multicolumn{9}{|c|}{ Response Variable } \\
\hline & \multicolumn{3}{|c|}{$d_{\mathrm{t}}$} & \multicolumn{3}{|c|}{$i d_{5}$} & \multicolumn{3}{|c|}{$\ln \left(i d_{5}+0.01\right)$} \\
\hline & \multirow[b]{2}{*}{ OLS } & \multicolumn{2}{|c|}{ LMM } & \multirow[b]{2}{*}{ OLS } & \multicolumn{2}{|c|}{ LMM } & \multirow[b]{2}{*}{ OLS } & \multicolumn{2}{|c|}{ LMM } \\
\hline & & Fixed & $\begin{array}{l}\text { Fixed \& } \\
\text { Random }\end{array}$ & & Fixed & $\begin{array}{l}\text { Fixed \& } \\
\text { Random }\end{array}$ & & Fixed & $\begin{array}{l}\text { Fixed \& } \\
\text { Random }\end{array}$ \\
\hline$\overline{M S E}$ & 2.265 & 2.273 & 2.175 & 2.222 & 2.22 & 2.115 & 2.397 & 2.311 & 2.226 \\
\hline$R M S E$ & 1.505 & 1.508 & 1.475 & 1.491 & 1.49 & 1.454 & 1.548 & 1.52 & 1.492 \\
\hline$R M S E \%$ & 6.868 & 6.881 & 6.732 & 6.803 & 6.8 & 6.637 & 7.066 & 6.939 & 6.81 \\
\hline$B I A S$ & 0.083 & 0.076 & 0.104 & 0.13 & 0.072 & 0.132 & -0.069 & -0.036 & -0.053 \\
\hline$B I A S \%$ & 0.378 & 0.346 & 0.477 & 0.594 & 0.329 & 0.601 & -0.317 & -0.165 & -0.24 \\
\hline$M A D$ & 0.863 & 0.853 & 0.81 & 0.819 & 0.814 & 0.749 & 0.869 & 0.836 & 0.801 \\
\hline$R^{2}$ & 0.951 & 0.951 & 0.953 & 0.952 & 0.952 & 0.954 & 0.948 & 0.95 & 0.952 \\
\hline
\end{tabular}




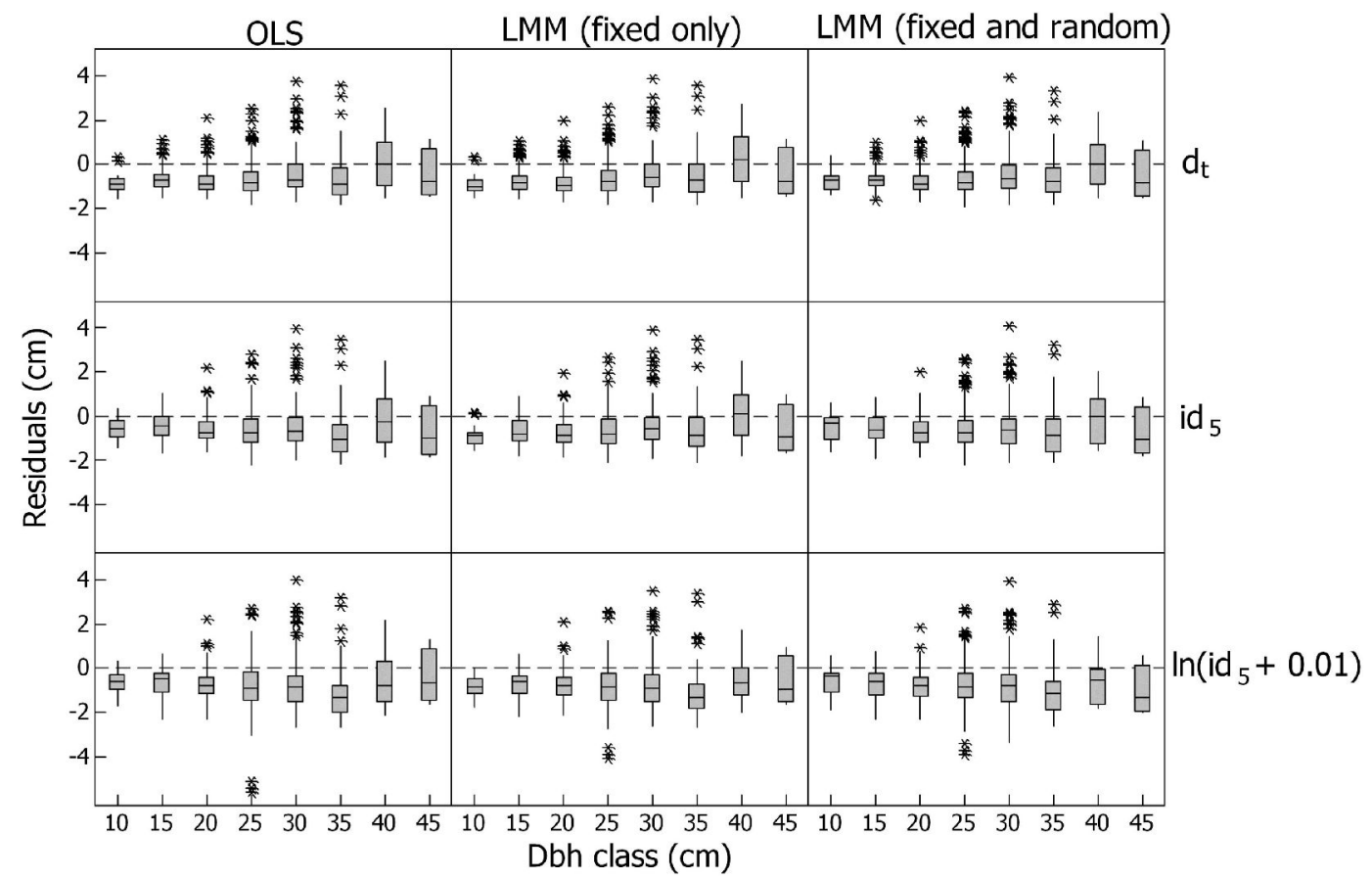

Fig. 2 - Residuals $v s$. predicted five-year diameter increment estimated with models with fixed and fixed plus random prediction in that order for the top row; fixed and fixed plus random prediction in the middle row; and fixed and fixed plus random prediction in the bottom row.

squares, linear mixed effect models considering only the fixed effects part and linear mixed effect models considering both the fixed and random effects of the model). Although the scale in the chart is small, it can be clearly seen that there is more noise in the bottom row corresponding to the natural $\log$ of diameter increment $\left[\ln \left(i d_{5}\right)\right]$ models, than in the first row (future diameter $d_{\mathrm{t}}$ models).

Continuing with the evaluation on the best OLS and LMM, we performed the proposed analysis on goodness-of-fit statistics on the best six model formulations. The results are presented on Tab. 4. The $d_{\mathrm{t}}$ model (eqn. 12) had better goodness-of-fit statistics when it was evaluated using the independent data set. It performed better in five out of seven statistics, although the margin of difference was narrow. Average error was under 5\% (1 $\mathrm{cm}$ ) over 5 years, and percent bias was less than $3 \%$. The $d_{5}$ model fitted by LMM corresponded reasonably well with the validation data, with a $R M S E=1.037 \mathrm{~cm}$. Model from eqn. 12 produced on average smaller residuals, ranging from 0.00 to $0.45 \mathrm{~cm}$ in the validation data set, and MSE ranged from 0.22 to $1.70 \mathrm{~cm}^{2}$.

To check for dependencies or systematic trends throughout the range of diameter classes, we proceeded to plot the residuals vs. predicted five-year diameter increment estimated with models with fixed and fixed plus random prediction in that order for the top row; fixed and fixed plus random prediction in the middle row; and fixed and fixed plus random prediction in the bottom row. The residuals did not exhibit dependencies or systematic trends; although the box and whiskers plot (Fig. 2) shows more narrow boxes for the top row which corresponds to model from eqn. 12, throughout the diameter classes. In general, model from eqn. 12 fitted by LMM slightly underestimates the diameter five years after initial measurement in all diameter classes.

\section{Discussion}

Diameter growth and yield prediction is one of the primary components of individual-tree growth models. These models allow detailed analyses on stand structure, but need additional equations to describe other components (e.g., tree mortality and recruitment) of tree or stand growth to make a complete stand or tree projection system. Diameter increment of $P$. occidentalis was studied as a stochastic process where a fixed part of a model explains the population-average increment, and a random component captures tree-to-tree variability. The study compares two statistical techniques, stepwise OLS regression and mixed models; two approaches, future diameter and diameter increment; and several classes of independent variables for predicting future diameter of $P$. occidentalis in La Sierra, Dominican Republic.

The best model was evaluated based on the seven goodness-of-fit statistics. Between the alternatives, the linear mixed model which included, for prediction purposes, both fixed and random effects was superior to just employing the fixed part of the LMM and ordinary least squares models. Modeling diameter through time as response variable was superior to the other two response variables, namely five-year diameter increment and its $\log$ transformation. The former resulted in a better fit, especially in regards to $M S E$, $R M S E, R M S E \%$ and $R^{2}$.

To detect prediction anomalies, one-to-one correspondence between observed vs. future predicted dbh were plotted in Fig. 2. No conspicuous anomalies were noted. The proposed formulation can be considered a projection model, containing a fixed part which explains the mean value for the future diameter and the unexplained residual variability is described by including random parameters. Model from eqn. 12 produces logical predictions of future $\mathrm{dbh}$, and by means of differentiation, dbh increment is easily obtained. The fixed components of model from eqn. 12 included initial tree size, elapsed time and $B A L$ as explanatory variables. Future diameter of a tree increased by approximately $4 \%$ on average for every centimeter added to initial dbh. Time contributed on average to $1 \%$ increment to the dbh reached five years hence.

Tree size is a good indicator of future growth, reflecting past competitive status and different genetic responses to the environment (Perry 1985, Bevilacqua 1999). With model from eqn. 12, diameter increment increased by a factor of 0.0903 for each unit increase in initial diameter. The positive sign associated with the parameter estimate of this variable may be a reflection of the low densities characterizing the studied plots. Previous results from density management trials in the study region have reported that for $P$. occidentalis stands older than 18 years of age, similar to those used in this study, the optimum residual density should be 700 trees per hectare $(T P H)$. In our study, the number of stems per hectare varied from 
192 to 950 , with 11 stands having at most $470 \mathrm{TPH}$, which is roughly $67 \%$ of the desired residual density. Seven stands were between 78 and $96 \%$, and four were slightly above $100 \%$ of the target residual density.

Variables commonly used to quantify competition and site productivity in individual tree diameter growth models, such as the number of trees per ha (West 1981), stand density index, basal area per hectare (Wycoff 1990) and site index (Palahí et al. 2003) were also tested in all the models evaluated. However, they were not significant in our best fitting model. Most surprisingly is the lack of predictive ability of site index, particularly since diameter increment appeared to be lowest in those stands geographically located along the dryer portion of the study region (1000 $\mathrm{mm}$ of average annual rainfall) These stands were also characterized by having very shallow sandy soils with depth between 30 and $50 \mathrm{~cm}$. Locations where diameter increment was larger, soil depth was between 80 and $100 \mathrm{~cm}$ and the average annual precipitation ranged from 1200 to 1600 $\mathrm{mm}$. It appears that height development for this species is not a good proxy for site productivity.

As basal area of larger trees $(B A L)$ increases, competition increases and that leads to a reduction in the diameter growth. That was manifested in the present study with the negative coefficient for this predictor variable. An increase of one unit in $B A L$ decreased future diameter by $0.2 \%$, on average. $P$. occidentalis is an intolerant species that needs direct sunlight to grow at full potential. Basal area of larger trees is considered a variable that captures one-sided competition for light (Bevilacqua 1999). The stands studied were not crowded so the competition for light was not that severe and is reflected in the biologically logical but moderate influence of $B A L$ on diameter growth.

The $R$ matrix in the model from eqn. 12 indicates significant random variability among trees. This suggests that other tree variables may need to be considered in the model. In terms of variability, model from eqn. $12 \mathrm{de}-$ tected larger quantities between trees $(0.355)$ than between plots (0.049). Pukkala (1989) attributes this phenomenon to human error in diameter increment measurement. In our case, the reason behind this pattern of variability may be found on the disparate arrangement of densities among the stand studied. These results are consistent with the findings of Palahí et al. (2003) when modeling growth for Pinus silvestrys L. in northeast Spain and contrary to the findings of Calama \& Montero (2005) for Pinus pinea, also in Spain.

Application of the fixed and random part of the model results in slightly biased estimates (less than $0.45 \mathrm{~cm}$ ) of the future diameter for trees larger than $40 \mathrm{~cm}$. For trees up to 28 $\mathrm{cm}$, biased is less than $0.10 \mathrm{~cm}$. In the validation dataset, $97 \%$ of the total variability in projected future diameter was explained by model from eqn. 12.

In Tab. 3, we explored the effects of the covariates included in model from eqn. 12. It remains unclear whether inclusion of random effects is an improvement over adding additional appropriate predictor variables. The presence of $B A L$ in the model decreased the values from the $G$ and $R$ matrices by 92 and 4 percent, respectively (Tab. 2). AIC and BIC values are decreased by about $2 \%$. Comparing model predictions using independent validation data demonstrated that all the models had moderately improved fit statistics when random effects were included in the evaluation. The degree of improvement behaved in a similar manner for most fit statistics, with differences in the range of values for MSE, RMSE and RMSE\% of 0.53 , 0.23 and 1.05 , respectively. The absolute difference between the extreme values for bias and relative bias (\%) in all the models was 0.20 and 0.92 . The differences in values for $M A D$ were only 0.15 and $R^{2}$ values were practically equivalent. This might be due to the fact that most of the sites are relatively poor, and the models may be capturing a gradual deceleration in growth, even for the short time period represented by the data. Slow growth was noticed during the first few remeasurements, with little or no growth in the last. Some considerations can be hypothesized as responsible for the absence of growth.

Differences in the performance of the mixed and fixed models in individual tree growth and yield modeling have been reported by others. Adame et al. (2007), working with Quercus pyrenaica Willd, found that most of the variability in tree growth occurred at the within-stand level, rather than between stands. Uzoh \& Oliver (2008) reported that the best relationship between five-year periodic annual diameter increments of ponderosa pine trees was provided by linear mixed models. Other authors (Calama \& Montero 2005, Palahí et al. 2003) have considered random variability in modeling diameter increment. They reported increase improvement in the fitting process when mixed models including both fixed and random parameters were employed.

Within-stand variability could be the result of the density of the stands under study. Basal area per hectare varied from 9.3 to $31.3 \mathrm{~m}^{2} \mathrm{ha}^{-1}$, with 7 stands having less than $15 \mathrm{~m}^{2} \mathrm{ha}^{-1}, 9$ stands having between 15 and $20 \mathrm{~m}^{2}$ ha $^{-1}, 6$ stands between 20 and $25 \mathrm{~m}^{2}$ $\mathrm{ha}^{-1}$, and three stands with more than $25 \mathrm{~m}^{2}$ $h^{-1}$. Stands with lower density have more space and resources available for tree growth. Even though it was tested, stand basal area was not a significant predictor variable in model from eqn. 12 . Perhaps its effect is being captured by the random part of the model.

\section{Conclusions}

We have determined that linear mixed models are the best statistical technique to fit linear regression models, for predicting dbh over time in $P$. occidentalis trees in $\mathrm{La}$ Sierra, Dominican Republic. The proposed future diameter model from eqn. 12 prevailed over five-year diameter increment as the more appropriate response variable to model for predicting future dbh, using variables related to tree size such as initial dbh $\left(d_{0}\right)$, elapsed time $(t)$, and variables related to competition like the cumulative basal area of the trees larger than subject tree $\left(B A L_{0}\right)$ as predictor variables. Model from eqn. 12 does not depend on age or distance. The final predictor variables were selected based on their ecological importance to tree growth and on fitting statistics. Simulations performed with model from eqn. 12 showed that coefficients for predictor variables were biologically appropriate. Specifically, larger trees $\left(d_{0}\right)$ grew faster, trees growing in stands having higher densities $\left(T P H_{0}\right)$ grow slower, and increasing levels of competition at the tree level $\left(B A L_{0}\right)$ also decreased predicted future diameter.

Based on Akaike's Information Criterion and the Bayesian's Information Criterion, the most appropriate covariance structures was the unstructured (UN). The adequacy of the covariance structure was confirmed by the likelihood ratio test which was statistically significant $(p<0.0001)$. Evidence reported in Tab. 3 shows that the linear mixed models tested produced better fit statistics when plots were considered as random effects. This confirms our expectations that the inclusion of fixed plus random effects was more effective than including only fixed effects in the predictions of future dbh.

This study is the first attempt to model individual tree growth of $P$. occidentalis in the Dominican Republic. Model evaluation is an uninterrupted course of action, and the results from this study can be further improved in the immediate future. For the moment, the model will enable estimation of diameter on individual $P$. occidentalis trees in the north central portion of Cordillera Central, for up to five years in the future, based on information regarding initial $\mathrm{dbh}$ and basal area of trees within stands. The species has great economic, ecological and social importance, and model from eqn. 12 can provide valuable information for decision-makers, forest managers and researchers. It is biologically consistent according to forest growth expectation, but projections longer than 5 years should be avoided until validation of the model using longer term data becomes available. The model should be simple to apply and can be used to facilitate and ensure the sustainable management of $P$. occidentalis. 


\section{Acknowledgements}

We want to express our gratitude to Drs. Ralph D. Nyland, Lianjun Zhang and Edwin $\mathrm{H}$. White for reviewing and suggesting their valuable inputs. Funding for this project was provided by the J. William Fulbright Foreign Scholarship Board (FSB), and by the Graduate Assistantship program at the State University of New York, College of Environmental Science and Forestry and the Collegiate Science and Technology. Major contributions were received from the Dominican government through Ministerio de Educacion Superior Ciencia y Tecnologia and its funding program (FONDOCYT). We also like to thank the Program on Latin America and the Caribbean at Syracuse University (PLACA), Cooperativa San José, Plan Sierra Inc., and PROCARYN.

\section{References}

Adame P, Hynynen J, Cañellas I, Del Rio M (2007). Individual-tree diameter growth model for rebollo oak (Quercus pyrenaica Willd.) coppices. Forest Ecology and Management 255: 1011-1022. - doi: 10.1016/j.foreco.2007.10.019 Baskerville GL (1972). Use of logarithmic regression in the estimation of plant biomass. Canadian Journal of Forest Research 2 (1): 49-53. doi: 10.1139/x72-009

Bevilacqua E (1999). Growth responses in individual eastern white pine (Pinus strobus L) trees following partial cutting treatments. PhD Dissertation, University of Toronto, Ontario, Canada, pp. 137.

Bueno-López SW (2009). Understanding growth and yield of Pinus occidentalis Sw. in La Sierra, Dominican Republic. PhD Dissertation, College of Environmental Science and Forestry, State University of New York, Syracuse, NY, USA, pp. 266.

Bueno-López SW, Bevilacqua E (2011). Developing a diameter-distribution prediction system for Pinus occidentalis Sw. in La Sierra, Dominican Republic. Revista Chapingo, Serie Ciencias Forestales y del Ambiente 17 (1): 115-132. [in Spanish]

Bueno-López SW, Bevilacqua E (2012). Nonlinear mixed model approaches to estimating merchantable bole volume for Pinus occidentalis. iForest 5 (5): 274-254. - doi: 10.3832/ifor0630005

Calama R, Montero G (2005). Multilevel linear mixed model for tree diameter increment in Stone pine (Pinus pinea): a calibrating approach.
Silva Fennica 39: 37-54. [online] URL: http:// metla.eu/silvafennica/full/sf39/sf391037.pdf Davis LS, Johnson KN (1987). Forest management. McGraw-Hill Company, New York, USA, pp. 790 .

Dobler G, Peralta LE, Debord LT, Torres JG (1995). Investigación y manejo de especies maderables de uso comun en La Sierra: guía técnica. San José de las Matas, Plan Sierra Inc., Republica Dominicana, pp. 269. [in Spanish]

Farjon A, Perez-De la Rosa JA, Styles BT (1997). A field guide to the pines of Mexico and Central America. The Royal Botanic Gardens, Kew, UK. Garrett MF, Laird NM, Ware JH (2004). Applied longitudinal analysis. Wiley-Interscience, John Wiley \& Sons, Inc., New Jersey, USA, pp. 536. Gregoire TG, Schabenberger O (1995). A nonlinear mixed-effects model to predict cumulative bole volume of standing trees. Journal of Applied Statistics 23: 257-271. - doi: 10.1080/0266476 9624233

Gutzwiller KJ, Riffell SK (2007). Using statistical models to study temporal dynamics of animal-landscape relations. In: "Temporal Dimensions of Landscape Ecology: Wildlife Responses to Variable Resources" (Bissonette JA, Storch I eds). Spinger-Verlag, New York, USA.

Holdridge L (1987). Ecología basada en zonas de vida. Instituto Interamericano de Cooperación para la Agricultura, San José, Costa Rica.

Kiernan DH, Bevilacqua E, Nyland RD (2008). Individual-tree diameter growth model for sugar maple trees in uneven-aged northern hardwood stands under selection system. Forest Ecology and Management 256: 1579-1586. - doi: 10.1016/j.foreco.2008.06.015

Littell RC, Milliken GA, Stroup WW, Wolfinger RD (1996). SAS system for mixed models. SAS Institute Inc., Cary, NC, USA, pp. 633.

Monleon VJ (2004). A hierarchical model for tree height prediction. In: Proceedings of the "2003 Meeting of the American Statistical Association, Section on Statistics and the Environment". San Francisco (CA - USA) 3-7 August 2003. The American Statistical Association, Alexandria, VA, USA, pp. 2865-2869.

Palahí M, Pukkala T, Miina J, Montero G (2003). Individual tree-growth and mortality models for Scots pine (Pinus sylvestrys L.) in north-east Spain. Annals of Forest Science 60: 1-10. - doi: 10.1051/forest:2003002

Perry DA (1985). The competition process in forest stands. In: "Attributes of trees as crop plants". Titus Wilson \& Son Ltd, Kendal, Cumbria, UK, pp. 592.
Popper KR (1963). Conjectures and refutations. Routledge and Kegan Paul, London, UK.

Pukkala T (1989). Predicting diameter growth in evenaged Scots pine stands with a spatial and non-spatial model. Silva Fennica 23: 101-116. [online] URL: http://hdl.handle.net/10138/15533 Reineke LH (1933). Perfecting a stand-density index for even aged forest. Journal of Agricultural Research 46: 627-638.

Sanchez-Gonzalez M, Del Rio M, Canellas I, Montero G (2006). Distance independent tree diameter growth model for cork oak stands. Forest Ecology and Management 225: 262-270. doi: 10.1016/j.foreco.2006.01.002

SAS Institute Inc. (1996). SAS/STAT User's guide. SAS Institute Inc., Cary, North Carolina. pp. 213.

Swedforest Consulting AB (1992). Plan maestro sector forestal. Informe principal. Plan Sierra Inc., San José de las Matas, Santiago, Dominican Republic, pp. 82.

Uzoh FC, Oliver WW (2008). Individual tree diameter increment model for managed even-aged stands of ponderosa pine throughout the western United States using multilevel linear mixed effects models. Forest Ecology and Management 256: 438-445. - doi: 10.1016/j.foreco.2008.04. 046

Vanclay JK (1994). Modeling forest growth and yield: Applications to Mixed Tropical Forests, CAB International, Wallingford, CT, USA, pp. 312 .

West PW (1981). Simulation of diameter growth and mortality in regrowth eucalypt forest of Southern Tasmania. Forest Science 27: 603-616.

Westfall JA (2006). Predicting past and future diameter growth for trees in the northeastern United States. Canadian Journal of Forest Research 36: 1551-1562. - doi: 10.1139/x06-045

Wycoff W (1990). A basal area increment model for individual conifers in the northern Rocky Mountains. Forest Science 36: 1077-1104.

Zhang L, Gove JH (2005). Spatial assessment of model errors from four regression techniques. Forest Science 51 (4): 334-346.

Zhang L, Peng C, Dang Q (2004). Individual-tree basal area growth models for jack pine and black spruce in northern Ontario. Forestry Chronic 80 (3): 366-374. - doi: 10.5558/tfc80366-3

Zhao D, Borders B, Wilson M (2004). Individual-tree diameter growth and mortality models for bottomland mixed-species hardwood stands in the lower Mississippi alluvial valley. Forest Ecology and Management 199: 307-322. - doi: 10.1016/j.foreco.2004.05.043 